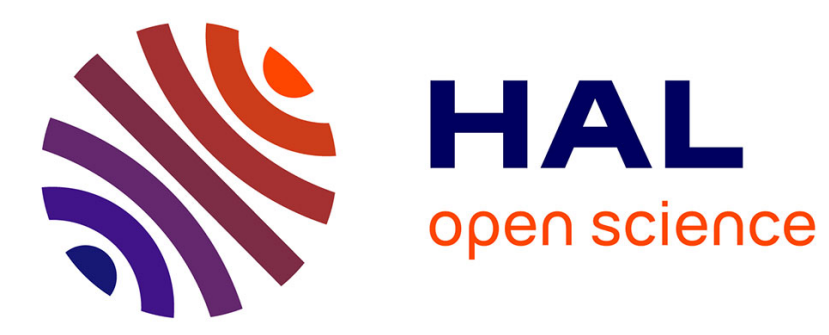

\title{
Harvest-induced maturation evolution under different life-history trade-offs and harvesting regimes
}

\author{
J.J. Poos, A. A. Brännström, U. Dieckmann
}

\section{To cite this version:}

J.J. Poos, A. Å. Brännström, U. Dieckmann. Harvest-induced maturation evolution under different life-history trade-offs and harvesting regimes. Journal of Theoretical Biology, 2011, 279 (1), pp.102. 10.1016/j.jtbi.2011.03.001 . hal-00694285

\section{HAL Id: hal-00694285 \\ https://hal.science/hal-00694285}

Submitted on 4 May 2012

HAL is a multi-disciplinary open access archive for the deposit and dissemination of scientific research documents, whether they are published or not. The documents may come from teaching and research institutions in France or abroad, or from public or private research centers.
L'archive ouverte pluridisciplinaire HAL, est destinée au dépôt et à la diffusion de documents scientifiques de niveau recherche, publiés ou non, émanant des établissements d'enseignement et de recherche français ou étrangers, des laboratoires publics ou privés. 


\section{Author's Accepted Manuscript}

Harvest-induced maturation evolution under different life-history trade-offs and harvesting regimes

J.J. Poos, Å. Brännström, U. Dieckmann

PII:

S0022-5193(11)00130-5

DOI:

doi:10.1016/j.jtbi.2011.03.001

Reference:

YJTBI 6394

To appear in: Journal of Theoretical Biology

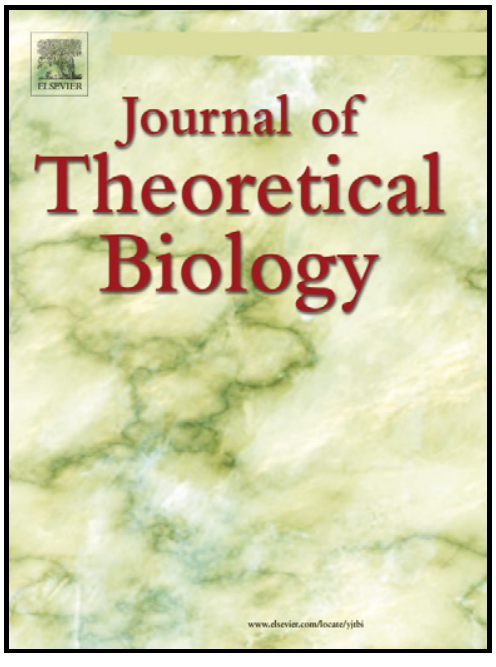

www.elsevier.com/locate/yjtbi

Received date: $\quad 2$ July 2010

Revised date: $\quad 21$ January 2011

Accepted date: $\quad 1$ March 2011

Cite this article as: J.J. Poos, Å. Brännström and U. Dieckmann, Harvest-induced maturation evolution under different life-history trade-offs and harvesting regimes, Journal of Theoretical Biology, doi:10.1016/j.jtbi.2011.03.001

This is a PDF file of an unedited manuscript that has been accepted for publication. As a service to our customers we are providing this early version of the manuscript. The manuscript will undergo copyediting, typesetting, and review of the resulting galley proof before it is published in its final citable form. Please note that during the production process errors may be discovered which could affect the content, and all legal disclaimers that apply to the journal pertain. 


\section{Harvest-induced maturation evolution} under different life-history trade-offs and harvesting regimes

\footnotetext{
J.J. Poos ${ }^{1,2, *}, \AA$ A. Brännström ${ }^{1,3}$, and U. Dieckmann ${ }^{1}$

${ }^{1}$ Evolution and Ecology Program, International Institute for Applied Systems Analysis, A2361, Laxenburg, Austria

${ }^{2}$ Wageningen IMARES, Institute for Marine Resources and Ecosystem Studies, PO Box 68, 1970 AB IJmuiden, The Netherlands

${ }^{3}$ Department of Mathematics and Mathematical Statistics, Umeå University, SE-90187, Umeå, Sweden

*Author for correspondence: E-mail: janjaap.poos@wur.nl
} 


\section{Abstract}

The potential of harvesting to induce adaptive changes in exploited populations is now increasingly recognized. While early studies predicted that elevated mortalities among larger individuals select for reduced maturation size, recent theoretical studies have shown conditions under which other, more complex evolutionary responses to size-selective mortality are expected. These new predictions are based on the assumption that, owing to the trade-off between growth and reproduction, earlier maturation implies reduced growth. Here we extend these findings by analyzing a model of a harvested size-structured population in continuous time, and by systematically exploring maturation evolution under all three traditionally acknowledged costs of early maturation: reduced fecundity, reduced growth, and/or increased natural mortality. We further extend this analysis to the two main types of harvest selectivity, with an individual's chance of getting harvested depending on its size and/or maturity stage. Surprisingly, we find that harvesting mature individuals not only favors late maturation when the costs of early maturation are low, but promotes early maturation when the costs of early maturation are high. To our knowledge, this study therefore is the first to show that harvesting mature individuals can induce early maturation. 


\section{Introduction}

Concerns over evolutionary consequences of harvesting are mounting, as both theoretical and empirical studies have demonstrated the potential for rapid harvest-induced evolution (e.g., Law, 2000; Conover and Munch, 2002; Heino and Godø, 2002; Ashley et al., 2003; Coltman et al., 2003; Jørgensen et al., 2007; Dieckmann et al., 2009). Life-history theory predicts that increased mortality devalues life-history processes occurring later in life, relative to those occurring earlier (e.g., Law 1979; Stearns, 1992; Ernande et al., 2004). Therefore, systematic reductions in age and size at maturation observed for stocks exposed to heavy fishing (e.g., Jørgensen, 1990; Rijnsdorp, 1993a; Trippel, 1995) are suggestive of fisheries-induced evolution (e.g., Heino et al., 2002; Grift et al., 2003, 2007; Barot et al., 2004, 2005; Olsen et al., 2004, 2005; Baulier et al., 2006; Dieckmann and Heino, 2007; Mollet et al., 2007; Heino and Dieckmann, 2008a, 2008b; Thériault et al., 2008; Arlinghaus et al., 2009; Okamoto et al., 2009). These concerns add to those raised more broadly about the negative impact of fisheries on the ecosystems in which all fish stocks are embedded (e.g., Jennings and Kaiser, 1998). Concerns are exacerbated by the fact that effects of fisheries-induced evolution are building up cumulatively, and by model-based results indicating that such effects will often be difficult and slow to reverse (Dunlop et al., 2009a; Enberg et al., 2009).

Earlier theoretical studies using age-structured models have shown that increased harvesting pressures may cause evolutionary shifts toward earlier maturation (Law and Grey, 1989; Heino, 1998; Ernande et al., 2004). The corresponding selection pressures are often enhanced when harvesting is positively size-selective, i.e., when larger fish are exploited more heavily than smaller fish. This picture has been complemented by recent studies demonstrating that in the presence of life-history trade-offs and/or predation, harvest-induced evolution may also result in delayed maturation (Gårdmark et al., 2003; Gårdmark and Dieckmann 2006). These newer predictions are based on specific assumptions about the trade-off between early maturation and growth, and therefore between early maturation and subsequent fecundity. Since there are several ways in which early maturation may cause fitness costs, and since the assumptions made about the resultant trade-offs are likely to impact the evolutionary predictions, further scrutiny of these dependences is warranted. As the major competing functions in an individual's allocation of available resources are reproduction, survival, and growth (e.g., Roff, 1983; Charnov and Berrigan, 1991; Arendt, 1997; Fonseca and Cabral, 2007), it is natural to consider that early maturation may result in reduced fecundity, reduced growth, and/or increased natural mortality. In this study, we systematically explore the evolutionary impacts of fishing under all these scenarios. 
Also, earlier theoretical studies of fisheries-induced evolution have largely focused on size-selective fishing. This reflects the fact that many of the world's fisheries are harvested size-selectively, because of gear design, targeting incentives of fishers, or management regulations (e.g., Holden, 1994; Hart and Reynolds, 2002; Fromentin and Powers, 2005). Some fisheries, however, may also be selective with respect to the maturity stage of individuals, irrespective of their size. While such an exploitation pattern is less common, it readily occurs when fisheries selectively target a stock's spawning grounds, like in the cases of Northeast Arctic cod (e.g., Garrod, 1967; Opdal, 2010) and Norwegian spring-spawning herring (e.g., Dragesund et al., 1980; Engelhard and Heino, 2004). At first sight, such stage-specific selectivity may appear to be very similar to size-specific harvesting, as mature individuals tend to be large individuals and vice versa. It is therefore important to realize that the evolutionary implications of stage-specific exploitation may surprisingly differ from those of size-specific exploitation. In this study, we systematically explore the evolutionary impacts of fishing under both scenarios.

In the following sections, we investigate maturation evolution in a size-structured continuous-time model of a selectively harvested population. In particular, we extend previous analyses by systematically exploring the evolutionary implications of (1) different fitness costs of early maturation, which may imply reduced fecundity, reduced growth, and/or increased natural mortality; and of (2) different selectivities of the harvesting regime, which may be based on size or on maturity stage.

\section{Model description}

We consider a harvested population divided into three size classes, as illustrated in Figure 1.

\subsection{Life-history processes}

Newborn individuals enter the first size class, grow into the second size class at rate $r_{1}$, and from there grow into the third size class. With probability $\gamma$, individuals mature when entering the second size class (early maturation); otherwise, they mature when entering the third size class (late maturation). Late-maturing individuals grow into the third size class at rate $r_{2}$, while early-maturing individuals grow into the third size class at rate $\tilde{r}_{2}$. Late-maturing individuals produce offspring at rate $f_{3}$, while early-maturing individuals produce offspring at rate $\tilde{f}_{2}$ in the second size class and at rate $\tilde{f}_{3}$ in the third. Late-maturing individuals experience mortality rates $m_{2}$ and $m_{3}$ in the second and third size class, respectively, while earlymaturing individuals experience the corresponding mortality rates $\tilde{m}_{2}$ and $m_{3}$. Natural mortality in the first size class is density-dependent and of logistic type, with carrying capacity 
$1 / m_{1}$. Harvesting is assumed to be density-independent and to occur in the second and/or third size classes, with rates of harvest mortality denoted by $h_{2}$ (individuals in the second size class that are late-maturing and thus immature), $\tilde{h}_{2}$ (individuals in the second size class that are early-maturing and thus mature), and $h_{3}$ (individuals in the third size class, which are all mature). The densities of individuals are denoted by $N_{1}$ (individuals in the first size class, which are all immature), $N_{2}$ (individuals in the second size class that are late-maturing and thus immature), $\tilde{N}_{2}$ (individuals in the second size class that are early-maturing and thus mature), $N_{3}$ (late-maturing individuals in the third size class, which are all mature), and $\tilde{N}_{3}$ (early-maturing individuals in the third size class, which are all mature). Quantities with a tilde always refer to the early-maturing life history. Table 1 provides an overview of all model variables and parameters.

\subsection{Life-history dynamics}

The dynamics of individuals in the first size class are given by

$$
\frac{d N_{1}}{d t}=\tilde{f}_{2} \tilde{N}_{2}+\tilde{f}_{3} \tilde{N}_{3}+f_{3} N_{3}-m_{1} N_{1}^{2}-r_{1} N_{1} .
$$

The first two terms on the right-hand side represent recruitment from early-maturing individuals, while the third term represents recruitment from late-maturing individuals. The last two terms represent density-dependent mortality in the first size class and growth into the second size class.

The dynamics of early- and late-maturing individuals in the second size class are given by, respectively,

$\frac{d \tilde{N}_{2}}{d t}=\gamma r_{1} N_{1}-\tilde{m}_{2} \tilde{N}_{2}-\tilde{h}_{2} \tilde{N}_{2}-\tilde{r}_{2} \tilde{N}_{2}$,

$$
\frac{d N_{2}}{d t}=(1-\gamma) r_{1} N_{1}-m_{2} N_{2}-h_{2} N_{2}-r_{2} N_{2} .
$$

From left to right, the terms represent growth from the first size class, natural mortality, harvest mortality, and growth into the third size class.

Finally, the dynamics of early- and late-maturing individuals in the third size class are given by, respectively,

$$
\begin{aligned}
& \frac{d \tilde{N}_{3}}{d t}=\tilde{r}_{2} \tilde{N}_{2}-m_{3} \tilde{N}_{3}-h_{3} \tilde{N}_{3}, \\
& \frac{d N_{3}}{d t}=r_{2} N_{2}-m_{3} N_{3}-h_{3} N_{3} .
\end{aligned}
$$


From left to right, the terms represent growth from the second size class, natural mortality, and harvest mortality.

\subsection{Life-history trade-offs}

To explore maturation evolution in our model, we examine adaptations in the probability $\gamma$ that an individual matures early. Like Gårdmark et al. (2003), we assume that earlier maturation incurs life-history costs arising from energy-budget considerations. Limits in the energy individuals can allocate to different life-history functions naturally result in trade-offs between early maturation and reduced fecundity $\left(\tilde{f}_{3}<f_{3}\right)$, reduced growth $\left(\tilde{r}_{2}<r_{2}\right)$, and/or increased natural mortality $\left(\tilde{m}_{2}>m_{2}\right)$. Based on these trade-offs and the dynamics specified above, we now investigate the selection pressures harvesting imposes on the quantitative trait $\gamma$.

\section{Evolutionary consequences of size-specific harvesting}

To determine the fitness differences between early- and late-maturing individuals, we consider their basic reproduction ratio,

$$
R_{0}=F_{2} T_{2}+F_{3} T_{3},
$$

where $F_{2}$ and $F_{3}$ denote, respectively, the average fecundity rate of an individual in the second and third size class, while $T_{2}$ and $T_{3}$ denote the average time individuals spend in these two size classes. Early maturation increases $F_{2}$, but the trade-offs with growth, mortality, and/or fecundity will additionally affect $T_{2}, T_{3}$, and/or $F_{3}$, making the overall effect on $R_{0}$ hard to intuit. Table 2 summarizes the qualitative impacts that early maturation has on $F_{2}$, $F_{3}, T_{2}$, and $T_{3}$ under the three types of trade-offs. To proceed, a quantitative analysis is required.

\subsection{Evolutionary invasion analysis}

With $R_{0}=\gamma R_{0}^{1}+(1-\gamma) R_{0}^{0}$, where $R_{0}^{1}$ and $R_{0}^{0}$ are the basic reproduction ratios for early- and late-maturing individuals, respectively, we see that early maturation is favored by selection if and only if $R_{0}^{1}>R_{0}^{0}$ (bang-bang control; Sonneborn and Van Vleck, 1965). In Appendix A, we show that this inequality is equivalent to

$$
\tilde{D}_{2} \tilde{f}_{2}>r_{2} D_{2} D_{3} f_{3}-\tilde{r}_{2} \tilde{D}_{2} D_{3} \tilde{f}_{3},
$$

where $D_{i}$ denotes the average time that a late-maturing individual entering size class $i=2,3$ will remain in that size class. Likewise, $\tilde{D}_{2}$ denotes the average time that an early-maturing 
individual entering the second size class will remain in that size class. The difference between $D_{i}$ and $\tilde{D}_{i}$ on the one hand, and $T_{i}$ on the other, is that the former measure the average time an individual entering a size class will remain there, whereas the latter measure the average time a newborn individual will stay in size class $i$ during the course of its life. Ineq. (5) can be interpreted as describing a trade-off between the fitness gains due to early maturation in the second size class and the fitness losses due to early maturation in the third size class that result from reduced fecundity rate, reduced growth rate, and/or increased natural mortality rate.

The expected duration individuals spend in a size class is given by the inverse of their exit rate from that size class,

$$
D_{2}=\frac{1}{m_{2}+h_{2}+r_{2}}, \tilde{D}_{2}=\frac{1}{\tilde{m}_{2}+\tilde{h}_{2}+\tilde{r}_{2}}, \text { and } D_{3}=\frac{1}{m_{3}+h_{3}} .
$$

Substituting Eqs. (6) into Ineq. (5) and reorganizing shows that early maturation is favored by selection if and only if

$$
\tilde{f}_{2}>\frac{1}{m_{3}+h_{3}}\left(\frac{\tilde{m}_{2}+\tilde{h}_{2}+\tilde{r}_{2}}{m_{2}+h_{2}+r_{2}} r_{2} f_{3}-\tilde{r}_{2} \tilde{f}_{3}\right)
$$

This inequality allows us to conclude that harvesting the third size class always promotes early maturation. The consequences of harvesting the second size class at a stage-unspecific rate $h_{2}=\tilde{h}_{2}$ are less obvious and are examined below for each of the three potential costs of early maturation. It should be noted, however, that too high harvest mortality rates may cause the population to go extinct. Hence, conclusions drawn from Ineq. (7) are meaningful only for parameter values at which the population persists. A comprehensive graphical representation of possible outcomes of harvesting the second size class, also accounting for the exploitation limits at which the population goes extinct, is given in Fig. 2.

\subsection{Trade-off between early reproduction and fecundity rate}

Assuming that the only cost of early maturation is reduced fecundity in the third size class, $\tilde{f}_{3}<f_{3}$, Ineq. (7) simplifies to

$$
\tilde{f}_{2}>\frac{r_{2}\left(f_{3}-\tilde{f}_{3}\right)}{m_{3}+h_{3}}
$$

In this case, harvesting the second size class does not affect maturation evolution. This is because an increased mortality rate in the second size class equally reduces an individual's probability of reaching the third size class and its time spent in the second size class. 


\subsection{Trade-off between early reproduction and growth rate}

When early maturation reduces the growth rate of mature individuals, $\tilde{r}_{2}<r_{2}$, Ineq. (7) simplifies to

$$
\tilde{f}_{2}>\frac{f_{3}\left(m_{2}+h_{2}\right)\left(r_{2}-\widetilde{r}_{2}\right)}{\left(m_{3}+h_{3}\right)\left(m_{2}+h_{2}+r_{2}\right)} .
$$

In contrast to the preceding case, the mortality rates in the second size class do affect this inequality, and may therefore cause maturation evolution. Harvesting individuals in the second size class causes the right-hand side of Ineq. (9) to increase, thus making early maturation less advantageous.

\subsection{Trade-off between early maturation and mortality rate}

When early maturation increases the natural mortality rate of mature individuals in the second size class, $\tilde{m}_{2}>m_{2}$, Ineq. (7) simplifies to

$$
\tilde{f}_{2}>\frac{f_{3} r_{2}\left(\widetilde{m}_{2}-m_{2}\right)}{\left(m_{3}+h_{3}\right)\left(m_{2}+h_{2}+r_{2}\right)} .
$$

Here, the right-hand side decreases if the harvesting mortality rate increases, so harvesting the second size class makes early maturation more advantageous.

\subsection{Multiple trade-offs associated with early maturation}

The analysis above shows how the evolutionary effects of harvesting the second size class vary with the considered trade-off. To understand what happens when the three trade-offs are considered simultaneously, we denote by $f_{2}^{*}$ the right-hand side of Ineq. (7) for $h_{2}=\tilde{h}_{2}$, and calculate the first derivative of $f_{2}^{*}$ with respect to $h_{2}$,

$$
\frac{\partial f_{2}^{*}}{\partial h_{2}}=\frac{f_{3} r_{2}\left(m_{2}-\tilde{m}_{2}+r_{2}-\tilde{r}_{2}\right)}{\left(m_{3}+h_{3}\right)\left(m_{2}+h_{2}+r_{2}\right)^{2}} .
$$

We see that the sign of this derivative depends only on $m_{2}-\tilde{m}_{2}+r_{2}-\tilde{r}_{2}$ : harvesting the second size class makes early maturation more (less) advantageous if $m_{2}-\tilde{m}_{2}+r_{2}-\tilde{r}_{2}<(>) 0$, i.e., if $\tilde{m}_{2}-m_{2}>(<) r_{2}-\tilde{r}_{2}$, i.e., if the increase in mortality rate caused by early maturation is larger (smaller) than the decrease in growth rate caused by early maturation.

\subsection{Conclusion}

We have analyzed the effects of size-specific harvesting on maturation evolution for three potential costs of early maturation: reduced fecundity, reduced growth, and/or increased natural 
mortality. Results are summarized in Table 3: harvesting the smallest size class has no effect on maturation evolution, harvesting the intermediate size class can favor either early maturation (when mortality costs exceed growth costs) or late maturation (when growth costs exceed mortality costs), while harvesting the largest size class always favors early maturation. As noted in Sec. 3.1, our analysis applies to the full parameter ranges in which the population remains extant. In Fig. 3, we demonstrate that each of the predicted outcomes does indeed occur.

\section{Evolutionary consequences of stage-specific harvesting}

Using an analysis similar to that in the previous section, we can explore the effects of stagespecific harvesting, to examine the evolutionary consequences we expect from harvesting either mature or immature individuals. This scenario applies when fisheries selectively target a stock's spawning grounds or nursery grounds.

\subsection{Evolutionary invasion analysis}

We first analyze the case of stage-specific harvesting in which only immature individuals are harvested: $\tilde{h}_{2}=h_{3}=0$ and $h_{2}=h_{\mathrm{imm}}$. From Ineq. (7), we see that early maturation is advantageous if and only if

$$
\widetilde{f}_{2}>\frac{1}{m_{3}}\left(\frac{\tilde{m}_{2}+\widetilde{r}_{2}}{m_{2}+h_{\mathrm{imm}}+r_{2}} r_{2} f_{3}-\widetilde{r}_{2} \widetilde{f}_{3}\right) .
$$

The evolutionary effects caused by the harvesting of immature individuals depend on whether the right-hand side of this inequality increases or decreases with respect to the harvest mortality rate $h_{\mathrm{imm}}$, given that the population persists. Since the right-hand side of Ineq. (12) is a decreasing function of $h_{\mathrm{imm}}$, harvesting immature individuals always promotes early maturation. This is true for any combination of costs of early maturation we may consider. The biological interpretation of this result derives from the fact that maturation in the second size class offers an effective refuge from a harvesting regime that exploits only immature individuals.

We now turn to stage-specific harvesting regimes that target only mature individuals: $h_{2}=0$ and $\tilde{h}_{2}=h_{3}=h_{\text {mat }}$. From Ineq. (7), we see that early maturation is then favored by selection if and only if

$$
\widetilde{f}_{2}>\frac{1}{m_{3}+h_{\text {mat }}}\left(\frac{\widetilde{m}_{2}+h_{\mathrm{mat}}+\widetilde{r}_{2}}{m_{2}+r_{2}} r_{2} f_{3}-\widetilde{r}_{2} \widetilde{f}_{3}\right) .
$$


As the evolutionary consequences of harvesting mature individuals are difficult to elucidate when multiple trade-offs are considered simultaneously, we explore these consequences for each of the three trade-offs in turn.

\subsection{Trade-off between early reproduction and fecundity rate}

When the sole cost of early maturation is a reduced fecundity rate in the third size class, the consequences of harvesting mature individuals are found by setting $\tilde{r}_{2}=r_{2}$ and $\tilde{m}_{2}=m_{2}$ and differentiating the right-hand side of Ineq. (13) with respect to $h_{\text {mat }}$. In Appendix B, we show that the sign of this derivative is positive for small positive values of $f_{3}-\tilde{f}_{3}$, i.e., for small fecundity costs of early maturation. In that case, harvesting of mature individuals will make late maturation more advantageous. However, if the fecundity cost $f_{3}-\tilde{f}_{3}$ of early maturation is high, harvesting mature individuals may have the opposite effect, by making early maturation more advantageous.

\subsection{Trade-off between early reproduction and growth rate}

If early maturation instead induces slower growth from the second to the third size class, we find that the right-hand side of Ineq. (13) is an increasing function of $h_{\text {mat }}$ when

$$
\frac{\tilde{r}_{2}}{r_{2}}>1-\frac{m_{3}}{m_{2}}
$$

Thus, harvesting mature individuals makes late maturation more advantageous, independent of costs in terms of slower growth, if the natural mortality of late-maturing individuals is larger in the third size class than in the second. Otherwise, two disparate outcomes are possible. If the growth costs of early maturation are sufficiently small for Ineq. (14) to hold, i.e., if $\tilde{r}_{2}$ is not much smaller than $r_{2}$, harvesting mature individuals makes late maturation more advantageous. For larger costs of early maturation, harvesting of mature individuals has the opposite effect, by making early maturation more advantageous.

\subsection{Trade-off between early maturation and mortality rate}

Examining Ineq. (13) shows that when early maturation increases the natural mortality rate in the second size class, harvesting of mature individuals makes late maturation more advantageous when

$$
\tilde{m}_{2}-m_{2}<m_{3}
$$

i.e., when the mortality cost $\tilde{m}_{2}-m_{2}$ is low, but will have the opposite effect when this mortality cost exceeds the intrinsic mortality rate in the third size class. 


\subsection{Understanding the evolutionary outcomes}

The finding that harvesting mature individuals can induce not only late maturation (when costs of early maturation are low), but also early maturation (when costs of early maturation are high) is novel and surprising, but can be understood with the help of Fig. 1.

When costs of early maturation are negligible and harvesting is absent, early and late maturing individuals have very similar life histories, which differ only in the additional offspring early-maturing individuals produce in the second size class. Evidently, early maturation hence is the better strategy, but its advantage may be arbitrarily small. When mature individuals are harvested, this advantage is altered, since early-maturing individuals experience harvest mortality in both the second and the third size class, whereas late-maturing individuals experience harvesting mortality only in the third size class. Provided that the advantage of early maturation is not too large in the absence of harvesting, the differential impact of harvesting mature individuals will thus tip the evolutionary balance in favor of late maturation. This tendency is already well known and understood.

The reasons why harvesting mature individuals can induce early maturation when costs of early maturation are high are more subtle, and require appreciating two consequences of intensive harvesting: firstly, such harvesting makes it increasingly unlikely that early-maturing individuals reach the third size class, and secondly, it increasingly equalizes the expected durations early-maturing individuals spend in the second size class and late-maturing individuals spend in the third size class. Together, these effects imply a natural evolutionary advantage for early-maturing individuals under the intensive harvesting of mature individuals, since these individuals avoid the loss of time, and the resultant increase in mortality risk, that latematuring individuals experience in the second size class before they start to reproduce. Using these overarching observations, we now consider each life-history trade-off in turn.

When the trade-off between early maturation and fecundity rate is sufficiently strong, the third size class effectively acts as a reproductive sink for early-maturing individuals, exerting a high direct fitness cost of early maturation. In the absence of harvesting, this promotes late maturation. This fitness cost, however, becomes less and less relevant as the intensive harvesting of mature individuals increasingly prevents early-maturing individuals from reaching the third size class. Because of the natural evolutionary advantage of early maturation described above, such harvesting just needs to become intensive enough to tip the evolutionary balance in favor of early maturation.

When the trade-off between early maturation and growth rate is sufficiently strong, the growth of early-maturing individuals into the third size class is much impeded. If the natural 
mortality of late-maturing individuals is smaller in the third size class than in the second (Sect. 4.3), the expected duration that, in the absence of harvesting, late-maturing individuals spend in the third size class always exceeds that of early-maturing individuals in the second size class, which advantages late maturation. As the harvesting of mature individuals is increased, these durations become similar, so the aforementioned advantage of late maturation gradually disappears. At the same time, early-maturing individuals become unlikely to reach the third size class, whether they grow well or not, so the relative importance of the direct fitness cost of early maturation also gradually disappears. What remains is the natural evolutionary advantage of early maturation, which thus inevitably prevails once harvesting is intensive enough.

Finally, when the trade-off between early maturation and mortality rate is sufficiently strong, early-maturing individuals experience a higher natural mortality in the second size class. In the absence of harvesting, this promotes late maturation. As the harvesting of mature individuals is intensified, however, this direct fitness cost of early maturation is increasingly overshadowed by fishing mortality. Consequently, when such harvesting is intensive enough, the natural evolutionary advantage of early maturation will dominate the outcome.

For all three life-history trade-offs, the high direct fitness costs of early maturation, which favor late maturation in the absence of harvesting, thus gradually vanish as mature individuals are harvested intensively, uncovering the natural evolutionary advantage early maturation confers under such conditions.

\subsection{Conclusion}

We have analyzed the effects of stage-specific harvesting on maturation evolution for three potential costs of early maturation: reduced fecundity, reduced growth, and/or increased natural mortality. Results are summarized in Table 3. Harvesting immature individuals always favors early maturation. Harvesting mature individuals favors late maturation when the costs of early maturation are low. When natural mortality in the largest size class exceeds that in the intermediate size class, this conclusion remains true even when the growth costs of early maturation are arbitrarily high. For all other cases, high costs of early maturation can reverse the evolutionary consequence of harvesting mature individuals, so that such harvesting then makes early maturation more advantageous. In Fig. 4, we demonstrate that each of the predicted outcomes does indeed occur. 


\section{Discussion}

Here we have analyzed harvest-induced maturation evolution under different costs of early maturation and for harvest regimes with different selectivities. In particular, we have examined costs of early maturation that imply reduced fecundity, reduced growth, and/or increased natural mortality, while considering harvest regimes that are selective for either size or maturity stage. Our results provide a first systematic overview of how the evolutionary effects of harvesting vary with the trade-offs associated with early maturation and with the selectivities of harvesting regimes. The results of our investigation are summarized in Table 3 , and paraphrased in Secs. 3.6 and 4.5.

Life-history traits are often coupled through trade-offs (e.g., Charnov and Berrigan, 1991; Stearns, 1992). In this study we have therefore considered trade-offs between size at maturation and three major life-history characteristics: fecundity, growth, and mortality. These tradeoffs can affect maturation evolution by altering the underlying selection pressures. The importance of considering multiple trade-offs when studying harvest-induced maturation evolution is demonstrated by our results: selection pressures on size at maturation caused by size- or stage-specific harvesting vary, often qualitatively, with the considered life-history trade-offs.

Early maturation becomes advantageous when the benefits of reproducing early exceed the total costs of early reproduction. We find that when the cost of early maturation reduces fecundity in the largest size class, the mortality rate in the intermediate size class has no bearing on whether early or late maturation is advantageous. At first sight, this finding contrasts with earlier results obtained by Gårdmark et al. (2003). However, this difference between the continuous-time size-structured model studied here and the discrete-time age-structured model studied by Gårdmark et al. (2003) is unsurprising, since in our model a change in the mortality of the intermediate size class does not only affect the probability of reaching the largest size class, but also the time spent in the intermediate size class. This is not the case in the model by Gårdmark et al. (2003), where the time spent in the intermediate age class is fixed.

Harvest regimes are often selective in the sense that the mortality caused by fishing may depend on size, age, and/or maturity stage (e.g., Ajiad et al., 1999; Law, 2000). While agespecific harvesting is rare, size- and stage-specific harvesting are common. The results of our study underscore that the latter harvest selectivities can qualitatively change the outcomes of maturation evolution: harvesting intermediately sized or mature individuals can favor either early or late maturation (depending on the costs of early maturation), whereas harvesting large or immature individuals always favors early maturation. 
Previous studies have already shed some light on maturation evolution under harvest regimes that select for size or maturity stage. A study by Ernande et al. (2004) predicted that the harvesting of mature individuals induces maturation at an older age and larger size, whereas the harvesting of immature individuals induces maturation at a younger age and smaller size. Their work generalized earlier findings by Law and Grey (1989) and Heino (1998), which were obtained for directly evolving age or size at maturation, respectively, to ages and sizes at maturation that plastically varied with juvenile growth conditions. Our results differ from these findings by showing that harvesting of mature individuals may either increase or decrease the size at maturation that is favored by selection. Our results confirm findings by Gårdmark et al. (2006), who showed that evolutionary outcomes in size at maturation can both increase and decrease as a result of size-specific harvesting. Our results are novel by showing how the alternative fitness costs of early maturation determine the evolutionary consequences of harvesting.

For harvesting to decrease the size at maturation, the direct fitness cost of early maturation must be large. As an example, when this cost is expressed in terms of higher natural mortality, the harvesting of mature individuals may cause early maturation only if the additional mortality rate exceeds the natural mortality rate of the third size class. As another example, when the cost of early maturation is expressed in terms of lower growth, and natural mortality in the third size class is 10 percent lower than in the second, the harvesting of mature individuals may cause early maturation only if the early-maturing individuals grow 10 times slower than the late-maturing individuals. As a final example, when the cost of early maturation is expressed in terms of lower fecundity in the third size class, and the intrinsic growth and mortality rates are all equal, the fecundity must be reduced by half before harvesting mature individuals may cause early maturation.

With the number of empirical studies indicative of harvest-induced evolution in maturation schedules of commercially exploited marine fish stocks mounting rapidly (e.g., Grift et al., 2003, 2007; Olsen et al., 2004, 2005; Barot et al., 2005; Baulier et al., 2006; Mollet et al., 2007; Okamoto et al., 2009), it is becoming increasingly important to interpret observed trends in terms of sufficiently realistic eco-evolutionary models. Since, as a matter of principle, it will never be possible to prove fisheries-induced evolution as the unequivocal cause of maturation trends (Dieckmann and Heino, 2007), models are key to assessing whether the observed trends comply with those predicted by life-history theory: the closer the match, the more an interpretation of observed trends in terms of fisheries-induced evolution is strengthened. 
In response to this need, various eco-evolutionary modeling approaches have been devised and analyzed. The pioneering work by Law and Grey (1989) addressed harvest-induced maturation evolution in terms of simple age-structured population models (see also Rowell, 1993; Rijnsdorp, 1993b; Heino, 1998). Since then, several studies have extended the modeling of harvest-induced evolution to, e.g., natural predation (Gårdmark et al., 2003), phenotypically plastic growth and maturation (Ernande et al., 2004), the effects of marine reserves (Baskett et al., 2005; Dunlop et al., 2009b; Miethe et al., 2010), continuous size structure (Gårdmark and Dieckmann, 2006), density-dependent growth and genetic variation in multiple life-history traits (Dunlop et al., 2009a), density-dependent harvesting behavior (Arlinghaus et al., 2009), processes of stock recovery (Enberg et al., 2009), and explicit resource dynamics (Okamoto et al., 2009). The present study adds to this portfolio of modeling approaches by elucidating the effects of life-history trade-offs on harvest-induced maturation evolution.

A strong feature of the analysis presented here is that all results have been derived analytically, rather than through numerical explorations. Naturally, this benefit comes at the cost of a relatively simple model structure, defined by three size classes. As a particularly promising direction for future research, it will therefore be desirable to generalize our analysis to populations with continuous size structure, and if possible, with phenotypically plastic growth and maturation. Until then, our analysis can best be applied to natural populations by recognizing that our model's intermediate size class is to be defined as spanning the range of sizes over which maturation can naturally occur.

Predictions of our study can readily be judged against empirical observations of maturation evolution. Here we mention just a few examples. Positively size-selective fishing is common among stocks that are harvested by trawl fisheries. These gears generally have catch selectivity curves that increase with fish length (e.g., Millar, 1992). Examples of such stocks include North Sea sole and North Sea plaice, where both mature and immature fish experience positively size-selective harvest mortality rates. Our results summarized in Table 3, for the "Harvesting of size class 3", are compatible with the observed trends towards maturation at smaller size (Rijnsdorp, 1993; Grift et al., 2003, 2007; Mollet et al., 2007) observed for these and many other stocks.

Stage-specific fishing is common among stocks that undergo spawning migrations. Examples of such stocks include Northeast Arctic cod and Norwegian spring-spawning herring, where a strong spatio-temporal segregation of mature and immature fish enables targeted fisheries. Our results summarized in Table 3, for the "Harvesting of mature individuals", are compatible with the maturation sizes observed for Northeast Arctic cod until about the middle of the $20^{\text {th }}$ century, recognizing that these sizes were unusually large compared with all other 
stocks of Atlantic cod, that costs of early maturation are thought to be relatively low in this stock, and that the historical fishing regime had predominantly targeted mature individuals (Law and Grey, 1989; Jørgensen, 1990). Furthermore, our results summarized in Table 3, for the "Harvesting of immature individuals", are compatible with the maturation sizes observed for Northeast Arctic cod since about the middle of the $20^{\text {th }}$ century, recognizing that harvest mortality rates of immature Northeast Arctic cod in the Barents Sea has increased by a factor of approximately 5-7 from 1920 to 1960 . Finally, our results summarized in Table 3, for the "Harvesting of mature individuals", are compatible with the maturation sizes observed for Norwegian spring-spawning herring during the $20^{\text {th }}$ century. For this stock, a marked decrease in growth after maturation indicates that the trade-offs between early maturation and growth, and thus also between early maturation and future fecundity, are strong (Engelhard et al., 2003). In accordance with our results, the evolutionary changes in size at maturation caused by intense harvesting on the spawning grounds of Norwegian spring-spawning herring have been found to be very small (Engelhard and Heino, 2004).

In conclusion, we have systematically explored how different aspects of individual lifehistory characteristics and harvesting regimes affect the relative evolutionary advantage of early maturation. To keep the analysis tractable, the ecological environment - consisting of prey, competitors, and predators - has not been included in our model, even though it may have confounding effects on maturation evolution (e.g., Gårdmark et al., 2003). Despite this simplification, we hope that the insights on the evolutionary consequence of harvesting under different life-history trade-offs obtained in this study make a helpful contribution to the rapidly growing body of knowledge on fisheries-induced adaptive changes required for rational fisheries management.

\section{Acknowledgments}

JJP and UD are grateful for financial support by the Netherlands Organization for Scientific Research (NWO), in the form of a six-month postdoctoral scholarship that enabled JJP's work at IIASA. ÅB and UD acknowledges support by the European Marie Curie Research Training Network FishACE (Fisheries-induced Adaptive Changes in Exploited Stocks), funded through the European Community's Sixth Framework Programme (Contract MRTN-CT2004-005578). UD also acknowledges support by European Science Foundation, the Austrian Science Fund, the Austrian Ministry for Science and Research, and the Vienna Science and Technology Fund, as well as by the European Community's Sixth Framework Programme, through the Specific Targeted Research Project FinE ("Fisheries-induced evolution"). 


\section{References}

Ajiad, A., Jakobsen, T., Nakken, O., 1999. Sexual difference in maturation of Northeast Arctic cod. Journal of Northwest Atlantic Fisheries Science 25, 1-15.

Arendt, J.D., 1997. Adaptive intrinsic growth rates: an integration across taxa. The Quarterly Review of Biology 72, 149-177.

Arlinghaus, R., Matsumura, S., Dieckmann, U., 2009. Quantifying selection differentials caused by recreational fishing: development of modeling framework and application to reproductive investment in pike (Esox lucius). Evolutionary Applications 2, 335 355.

Ashley, M.V., Willson, M.F., Pergams, O.R.W., O’Dowd, D.J., Gende, S.M., Brown, J.S., 2003. Evolutionarily enlightened management. Biological Conservation 111, 115123.

Baskett, M.L., Levin, S.A., Gaines, S.D., Dushoff, J., 2005. Marine reserve design and the evolution of size at maturation in harvested fish. Ecological Applications 15, 882-901.

Barot, S., Heino, M., O’Brien, L., Dieckmann, U., 2004. Long-term trend in the maturation reaction norm of two cod stocks. Ecological Applications 14, 1257-1271.

Barot, S., Heino, M., Morgan, M.J., Dieckmann, U., 2005. Maturation of Newfoundland American plaice (Hippoglossoides platessoides): long-term trends in maturation reaction norms despite low fishing mortality? ICES Journal of Marine Science 62, 56-64.

Baulier, L., Heino, M., Lilly, G.R., Dieckmann, U., 2006. Body condition and evolution of maturation of Atlantic cod in Newfoundland. ICES CM 2006/H:19.

Charnov, E.L. and Berrigan, D., 1991. Evolution of life history parameters in animals with indeterminate growth, particularly fish. Evolutionary Ecology 5, 63-68.

Coltman, D.W., O’Donoghue, P., Jorgenson, J.T., Hogg, J.T., Strobeck, C., Festa-Bianchet, M., 2003. Undesirable evolutionary consequences of trophy hunting. Nature 426, 655-658.

Conover, D.O. and Munch, S.B., 2002. Sustaining fisheries yields over evolutionary time scales. Science 297, 94-96.

Dieckmann, U. and Heino, M., 2007. Probabilistic maturation reaction norms: their history, strengths, and limitations. Marine Ecology Progress Series 335, 253-269.

Dieckmann, U., Heino, M., Rijnsdorp, A.D., 2009. The dawn of Darwinian fishery management. ICES Insight 46, 34-43 
Dragesund, O., Hamre, J., Ulltang, Ø., 1980. Biology and population dynamics of the Norwegian spring spawning herring. Rapports et Procès-verbaux des Réunions Conseil International pour l'Exploration de la Mer 177, 43-71.

Dunlop, E.S., Heino, M., Dieckmann, U., 2009a. Eco-genetic modeling of contemporary lifehistory evolution. Ecological Applications 19, 1815-1834.

Dunlop, E.S., Baskett, M.L., Heino, M., Dieckmann, U., 2009b. Propensity of marine reserves to reduce the evolutionary impacts of fishing in a migratory species. Evolutionary Applications 2, 371-393.

Enberg, K., Dunlop, E.S., Jørgensen, C., Heino, M., Dieckmann, U., 2009. Implications of fisheries-induced evolution for stock rebuilding and recovery. Evolutionary Applications 2, 394-414.

Engelhard, G.H. and Heino, M., 2004. Maturity changes in Norwegian spring-spawning herring Clupea harengus: compensatory or evolutionary responses. Marine Ecology Progress Series 272, 245-256.

Engelhard, G.H., Dieckmann, U., Godø, O.R., 2003. Age at maturation predicted from routine scale measurements in Norwegian spring-spawning herring Clupea harengus using discriminant and neural network analyses. ICES Journal of Marine Science 60, 304313.

Ernande, B., Dieckmann, U., Heino, M., 2004. Adaptive changes in harvested populations: plasticity and evolution of age and size at maturation. Proceedings of the Royal Society, Series B, Biological Sciences 271, 415-423.

Fonseca, V.F. and Cabral, H.N., 2007. Are fish early growth and condition patterns related to life-history strategies? Reviews in Fish Biology and Fisheries 17, 545-564.

Fromentin, J.M. and Powers, J.E., 2005. Atlantic bluefin tuna: population dynamics, ecology, fisheries and management. Fish and Fisheries 6, 281-306.

Gårdmark, A. and Dieckmann, U., 2006. Disparate maturation adaptations to size-dependent mortality. Proceedings of the Royal Society, Series B, Biological Sciences 273, 21852192.

Gårdmark, A., Dieckmann, U., Lundberg, P., 2003. Life-history evolution in harvested populations: the role of natural predation. Evolutionary Ecology Research 5, 239-257.

Garrod, D.J., 1967. Population dynamics of the Arcto-Norwegian cod. Journal of the Fisheries Research Board of Canada 24, 145-190.

Grift, R.E., Rijnsdorp, A.D., Barot, S., Heino, M., Dieckmann, U., 2003. Fisheries-induced trends in reaction norms for maturation in North Sea plaice. Marine Ecology Progress Series 257, 247-257. 
Grift, R.E., Heino, M., Rijnsdorp, A.D., Kraak, S.B., Dieckmann, U., 2007. Threedimensional maturation reaction norms for North Sea plaice. Marine Ecology Progress Series 334, 213-224.

Hart, P.J.B. and Reynolds, J., 2002. Handbook of Fish Biology and Fisheries: Volume 2, Fisheries. Blackwell Science Ltd, Oxford (UK).

Heino, M., 1998. Management of evolving fish stocks. Canadian Journal of Fisheries and Aquatic Sciences 55, 1971-1982.

Heino, M. and Dieckmann, U., 2008a. Detecting fisheries-induced life-history evolution: an overview of the reaction norm approach. Bulletin of Marine Science 83, 69-93.

Heino, M. and Dieckmann, U., 2008b. Evolution and sustainability of harvested populations. In: Conservation Biology: Evolution in Action, eds. Carroll, S.P. and Fox, C., pp. 308323. Oxford University Press, Oxford (UK).

Heino, M. and Godø, O.R., 2002. Fisheries-induced selection pressures in the context of sustainable fisheries. Bulletin of Marine Science 70, 639-656.

Heino, M., Dieckmann, U., Godø, O.R., 2002. Measuring probabilistic reaction norms for age and size at maturation. Evolution 56, 669-678.

Holden, M., 1994. The Common Fisheries Policy. Fishing News Books, Oxford (UK).

Jennings, S. and Kaiser, M.J., 1998. The effects of fishing on marine ecosystems. Advances in Marine Biology 34, 201-352.

Jørgensen, C., Enberg, K., Dunlop, E.S., Arlinghaus, R., Boukal, D., Brander, K., Ernande, B., Gårdmark, A., Johnston, F., Matsumura, S., Pardoe, H., Raab, K., Silva, A., Vainikka, A., Dieckmann, U., Heino, M., Rijnsdorp, A.D., 2007. Managing evolving fish stocks. Science 318, 1247-1248.

Jørgensen, T., 1990. Long-term changes in age at sexual maturity of Northeast Arctic cod (Gadus morhua L.). Journal du Conseil International pour l'Exploration de la Mer 46, 235-248.

Law, R., 1979. Optimal life histories under age-specific predation. American Naturalist 114, 399-417.

Law, R., 2000. Fishing, selection, and phenotypic evolution. ICES Journal of Marine Science 57, 659-669.

Law, R. and Grey, D.R., 1989. Evolution of yields from populations with age-specific cropping. Evolutionary Ecology 3, 343-359.

Miethe, T., Dytham, C., Dieckmann, U., Pitchford, J., 2010. Marine reserves and the evolutionary effects of fishing on size at maturation. ICES Journal of Marine Science, in press; doi: 10.1093/icesjms/fsp248. 
Millar, R.B., 1992. Estimating the size-selectivity of fishing gear by conditioning on the total catch. Journal of the American Statistical Association 87, 962-968.

Mollet, F., Kraak, S.B.M., Rijnsdorp, A.D., 2007. Fisheries-induced evolutionary changes in maturation reaction norms in North Sea sole Solea solea. Marine Ecology Progress Series 351, 189-199.

Okamoto, K.W., Whitlock, R., Magnan, P., Dieckmann, U., 2009. Mitigating fisheriesinduced evolution in lacustrine brook charr (Salvelinus fontinalis) in southern Quebec, Canada. Evolutionary Applications 2, 415-437

Olsen, E.M., Heino, M., Lilly, G.R., Morgan, M.J., Brattey, J., Ernande, B., Dieckmann, U., 2004. Maturation trends indicative of rapid evolution preceded the collapse of northern cod. Nature 428, 932-935.

Olsen, E.M., Lilly, G.R., Heino, M., Morgan, M.J., Brattey, J., Dieckmann, U., 2005. Assessing changes in age and size at maturation in collapsing populations of Atlantic cod (Gadus morhua). Canadian Journal of Fisheries and Aquatic Sciences 62, 811-823.

Opdal, A.F., 2010. Fisheries change spawning ground distribution of northeast Arctic cod. Biology Letters, in press; doi:10.1098/rsbl.2009.0789.

Rijnsdorp, A.D., 1993a. Fisheries as a large-scale experiment on life-history evolution: disentangling phenotypic and genetic effects in changes in maturation and reproduction of North Sea plaice, Pleuronectes platessa L. Oecologia 96, 391-401.

Rijnsdorp, A.D., 1993b. Selection differentials in male and female North Sea plaice and changes in maturation and fecundity. In: Stokes, T.K., McGlade, J.M., Law, R. (Eds.), The Exploitation of Evolving Resource. Lecture Notes in Biomathematics, 99. Springer, Berlin, pp. 19-36

Roff, D.A., 1983. An allocation model of growth and reproduction in fish. Canadian Journal of Fisheries and Aquatic Sciences 40, 1395-1404.

Rowell, C.A., 1993. The effects of fishing on the timing of maturity in North Sea cod (Gadus morhua L.). In: Stokes, T.K., McGlade, J.M., Law, R. (Eds.), The Exploitation of Evolving Resource. Lecture Notes in Biomathematics, 99. Springer, Berlin, pp. 44-61.

Sonneborn, L.M. and Van Vleck, F.S., 1965. The bang-bang principle for linear control systems. Journal of the Society for Industrial and Applied Mathematics, Series A 2, 151159.

Stearns, S.C., 1992. The Evolution of Life Histories. Oxford University Press, New York.

Thériault, V., Dunlop, E.S., Dieckmann, U., Bernatchez, L., Dodson, J.J., 2008. The impact of fishing-induced mortality on the evolution of alternative life-history tactics in brook charr. Evolutionary Applications 1, 409-423. 
604 Trippel, E.A., 1995. Age at maturity as a stress indicator in fisheries. Bioscience 45, 759-771. 


\section{Appendix A: General invasion condition derived from basic reproduction ratio}

An individual's basic reproduction ratio $R_{0}$ equals its total lifetime reproductive output. For our model, this can be expressed as $R_{0}=F_{2} T_{2}+F_{3} T_{3}$, where $T_{2}$ and $T_{3}$ are the average times an individual will spend in the two larger size classes, and $F_{2}$ and $F_{3}$ are the average fecundity rates in these size classes.

Accounting for the fact that an individual may or may not mature early, we obtain

$$
T_{2}=\gamma P_{2} \tilde{D}_{2}+(1-\gamma) P_{2} D_{2}
$$

where $\gamma$ is the individual's probability to mature early (i.e., in the second size class), $P_{2}$ is its probability of surviving from entering the first size class until entering the second size class, while $\tilde{D}_{2}$ and $D_{2}$ are the average durations, respectively, that an early- and late-maturing individual entering the second size class will remain there. An individual's average fecundity rate $F_{2}$ in the second size class equals the average total number of offspring it has while staying in that size class, divided by the average time $T_{2}$ it spends in that size class,

$$
F_{2}=\frac{\gamma P_{2} \tilde{D}_{2} f_{2}}{\gamma P_{2} \tilde{D}_{2}+(1-\gamma) P_{2} D_{2}} .
$$

Analogously, the average time an individual spends in the third size class is

$$
T_{3}=\gamma P_{2} \tilde{P}_{3} D_{3}+(1-\gamma) P_{2} P_{3} D_{3}
$$

where $\tilde{P}_{3}$ and $P_{3}$, respectively, are the probabilities with which an early- and late-maturing individual entering the second size class will survive until entering the third size class. The average fecundity in the third size class is then given by

$$
F_{3}=\frac{\gamma \tilde{P}_{3} D_{3} \tilde{f}_{3}+(1-\gamma) P_{3} D_{3} f_{3}}{\gamma \tilde{P}_{3} D_{3}+(1-\gamma) P_{3} D_{3}} .
$$

For $R_{0}$, we thus obtain

$$
R_{0}=F_{2} T_{2}+F_{3} T_{3}=\gamma\left(P_{2} D_{2} \tilde{f}_{2}+P_{2} \tilde{P}_{3} D_{3} \tilde{f}_{3}\right)+(1-\gamma) P_{2} P_{3} D_{3} f_{3}
$$

This has to equal $R_{0}=\gamma R_{0}^{1}+(1-\gamma) R_{0}^{0}$, where $R_{0}^{1}$ and $R_{0}^{0}$, respectively, are the basic reproduction ratios for early- and late-maturing individuals. Selection favors early maturation $(\gamma=1)$ over late maturation $(\gamma=0)$ if and only if $R_{0}^{1}>R_{0}^{0}$. We can identify $R_{0}^{1}$ and $R_{0}^{0}$ from Eq. (A.5) to get

$$
P_{2} \tilde{D}_{2} f_{2}+P_{2} D_{3} \tilde{P}_{3} \tilde{f}_{3}>P_{2} P_{3} D_{3} f_{3}
$$

Since $P_{2}$ is positive, we can rewrite Ineq. (A.6) as 


$$
\tilde{D}_{2} f_{2}+D_{3} \tilde{P}_{3} \tilde{f}_{3}>P_{3} D_{3} f_{3} .
$$

The probability $P_{3}$ of an early-maturing individual entering the second size class to survive until entering the third size class is $r_{2} D_{2}$. Similarly, the probability $\tilde{P}_{3}$ of a late-maturing individual entering the second size class to survive until entering the third size class is $\tilde{r}_{2} \tilde{D}_{2}$. In conclusion, we therefore find that early maturation is favored by selection if

$$
\tilde{D}_{2} f_{2}>r_{2} D_{2} D_{3} f_{3}-\tilde{r}_{2} \tilde{D}_{2} D_{3} \tilde{f}_{3}
$$

\section{Appendix B: Specific invasion conditions for harvesting mature individuals}

We can determine whether the harvesting of mature individuals makes early maturation more or less evolutionarily advantageous by studying how a change in the harvest mortality rate $h_{\text {mat }}$ affects the right-hand side of Ineq. (13).

First, we assume that the only trade-off associated with early reproduction is a reduced fecundity in the third size class. Denoting by $f_{2}^{*}$ the right-hand side of Ineq. (13) for $\tilde{r}_{2}=r_{2}$ and $\tilde{m}_{2}=m_{2}$, and differentiating $f_{2}^{*}$ with respect to $h_{\text {mat }}$, we obtain

$$
\frac{\partial f_{2}^{*}}{\partial h_{\text {mat }}}=\frac{r_{2}\left(\tilde{f}_{3}\left(m_{2}+r_{2}\right)-f_{3}\left(m_{2}-m_{3}+r_{2}\right)\right)}{\left(h_{\text {mat }}+m_{3}\right)^{2}\left(m_{2}+r_{2}\right)} .
$$

The sign of this derivative depends only on the last factor in the numerator, and therefore is positive if and only if

$$
f_{3}-\tilde{f}_{3}<\frac{f_{3} m_{3}}{m_{2}+r_{2}}
$$

Consequently, $f_{2}^{*}$ is an increasing function of $h_{\text {mat }}$ when $f_{3}-\tilde{f}_{3}$ is small, i.e., harvesting mature individuals promotes late maturation when the fecundity costs of early maturation are low.

Second, we instead assume that the only trade-off associated with early maturation is a higher natural mortality in the second size class. Denoting by $f_{2}^{*}$ the right-hand side of Ineq. (13) for $\tilde{f}_{3}=f_{3}$ and $\tilde{r}_{2}=r_{2}$, and differentiating $f_{2}^{*}$ with respect to $h_{\text {mat }}$, we obtain

$$
\frac{\partial f_{2}^{*}}{\partial h_{\mathrm{mat}}}=\frac{r_{2} f_{3}\left(m_{2}-\tilde{m}_{2}+m_{3}\right)}{\left(h_{\mathrm{mat}}+m_{3}\right)^{2}\left(m_{2}+r_{2}\right)} .
$$

The last factor in the numerator shows that this derivative is positive if and only if

$$
\tilde{m}_{2}-m_{2}<m_{3},
$$


659

660

661

662

663

664

665

666

667

668

669

670

671

672

673

674

675

676

677

678

Consequently, $f_{2}^{*}$ is an increasing function of $h_{\text {mat }}$ when $\tilde{m}_{2}-m_{2}$ is small, i.e., harvesting mature individuals promotes late maturation when the mortality costs of early maturation are low.

Third, we instead assume that the only trade-off associated with early maturation is a lower growth rate from the second to the third size class. Denoting by $f_{2}^{*}$ the right-hand side of Ineq. (13) for $\tilde{f}_{3}=f_{3}$ and $\tilde{m}_{2}=m_{2}$, and differentiating $f_{2}^{*}$ with respect to $h_{\text {mat }}$, we obtain

$$
\frac{\partial f_{2}^{*}}{\partial h_{\mathrm{mat}}}=\frac{f_{3}\left(m_{3} r_{2}+m_{2}\left(\tilde{r}_{2}-r_{2}\right)\right)}{\left(h_{\mathrm{mat}}+m_{3}\right)^{2}\left(m_{2}+r_{2}\right)} .
$$

The last factor in the numerator shows that this derivative is positive if and only if

$$
\frac{\tilde{r}_{2}}{r_{2}}>1-\frac{m_{3}}{m_{2}} .
$$

For $m_{3}<m_{2}, f_{2}^{*}$ therefore is an increasing function of $h_{\text {mat }}$ when $\tilde{r}_{2} / r_{2}$ is sufficiently close to 1, i.e., harvesting mature individuals promotes late maturation when the growth costs of early maturation are low. For $m_{3}>m_{2}$, i.e., when the natural mortality rate in the third size class exceeds that in the second size class, Ineq. (B.7) holds independent of these growth costs. In that case, $f_{2}^{*}$ always is an increasing function of $h_{\text {mat }}$, so that harvesting mature individuals always promotes late maturation.

\section{Appendix C: Parameter values for numerical examples}

The analyses presented in Secs. 3 and 4 apply to the full parameter ranges for which the population persists, as illustrated in Fig. 2. In Figs. 3 and 4 we show that all predicted outcomes occur. To facilitate replication of these results, we provide in Table $\mathrm{C} 1$ the specific parameterizations that were used to produce each of the panels in Figs. 2-4. 


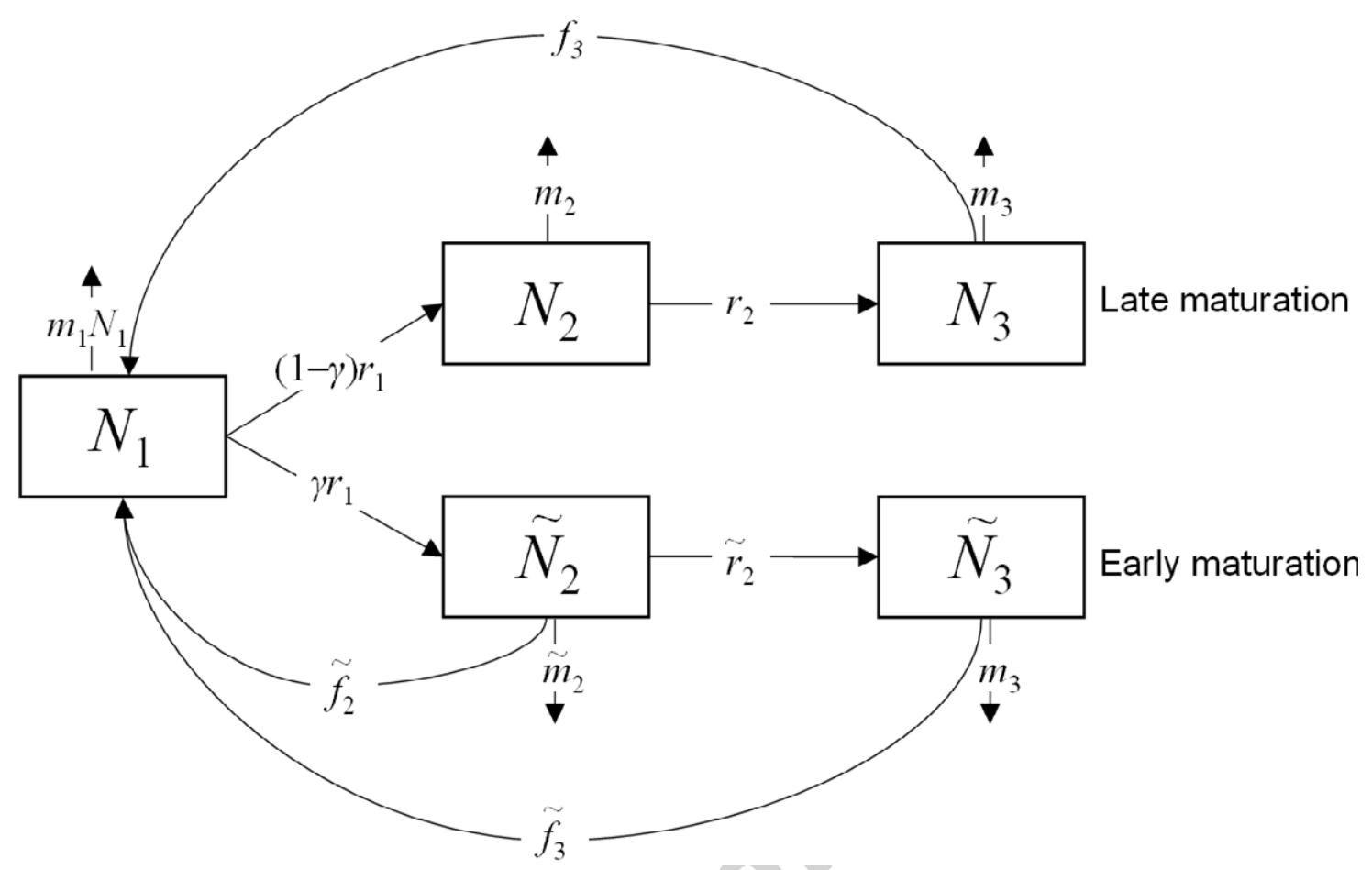

Figure 1. Schematic illustration of the size-structured continuous-time life-history model analyzed in this study. The harvested population is partitioned into small individuals (first size class, with density $N_{1}$ ), intermediately sized individuals (second size class, with densities $N_{2}$ and $\tilde{N}_{2}$ ), and large individuals (third size class, with densities $N_{3}$ and $\tilde{N}_{3}$ ). Individuals can mature early (with probability $\gamma$, bottom row) or late (with probability $1-\gamma$, top row). Quantities with a tilde refer to the early-maturing life history. The probability $\gamma$ of early maturation is evolving. The parameters $r_{1}, r_{2}$, and $\tilde{r}_{2}$ are growth rates; $\tilde{f}_{2}, f_{3}$, and $\tilde{f}_{3}$ are fecundity rates; $1 / m_{1}$ is the carrying capacity of the first size class; $m_{2}, \tilde{m}_{2}$, and $m_{3}$ are natural mortality rates; and $h_{2}, \tilde{h}_{2}$, and $h_{3}$ are harvest mortality rates. 

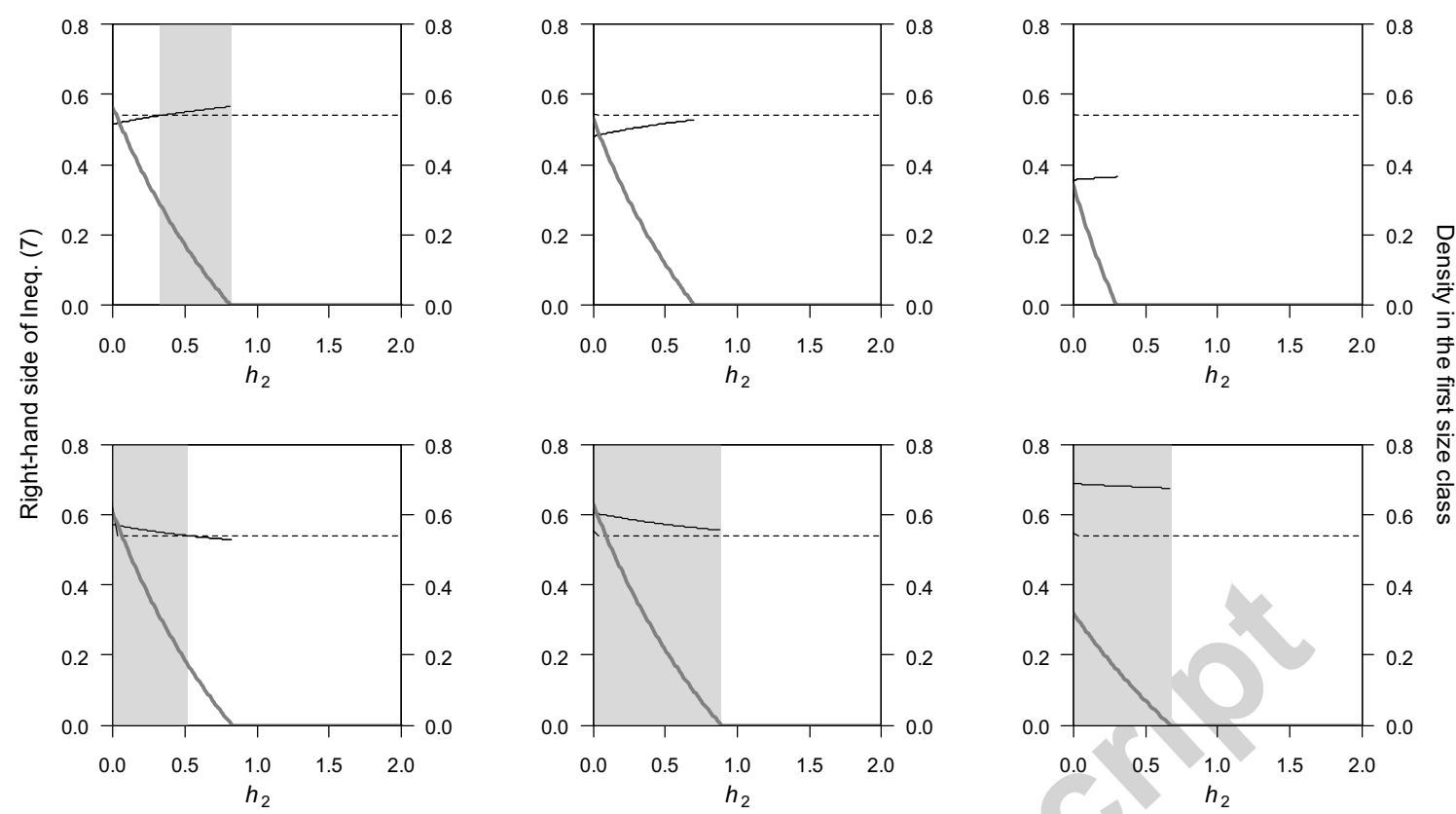

691

692

693

694

695

696

697

698

699

700

701

702

703

704

705

706

Figure 2. Numerical illustration of the possible evolutionary consequences of harvesting the second size class (increasing $h_{2}$ ). Harvesting the second size class can make maturation in either the second or the third size class advantageous. The population density $N_{1}$ of the first size class (thick gray line, right vertical axis) decreases with increased harvesting rate $h_{2}$. If harvesting rates are too high for the population to persist, model predictions are not meaningful. The right-hand side of Ineq. (7) (thin black line, left vertical axis) can either increase with $h_{2}$ (top panels) or decrease with $h_{2}$ (lower panels), depending on model parameters. When the thin black line is below $f_{2}$, marked here with a dashed horizontal line, Ineq. (7) is fulfilled and selection promotes early maturation. If instead the thin black line is above $f_{2}$, Ineq. (7) is not fulfilled and selection promotes late maturation (grey areas). As the harvesting rate is increased, there may be a switch in optimal maturation size (left panels). Alternatively, the switch in optimal maturation is predicted by the model at harvesting rates for which the population is no longer viable (central panels). Finally, model parameters can be chosen such that the switching point is never reached, independent of the harvesting rate (right panels). Parameter values are provided in Table $\mathrm{C} 1$ of Appendix $\mathrm{C}$. 

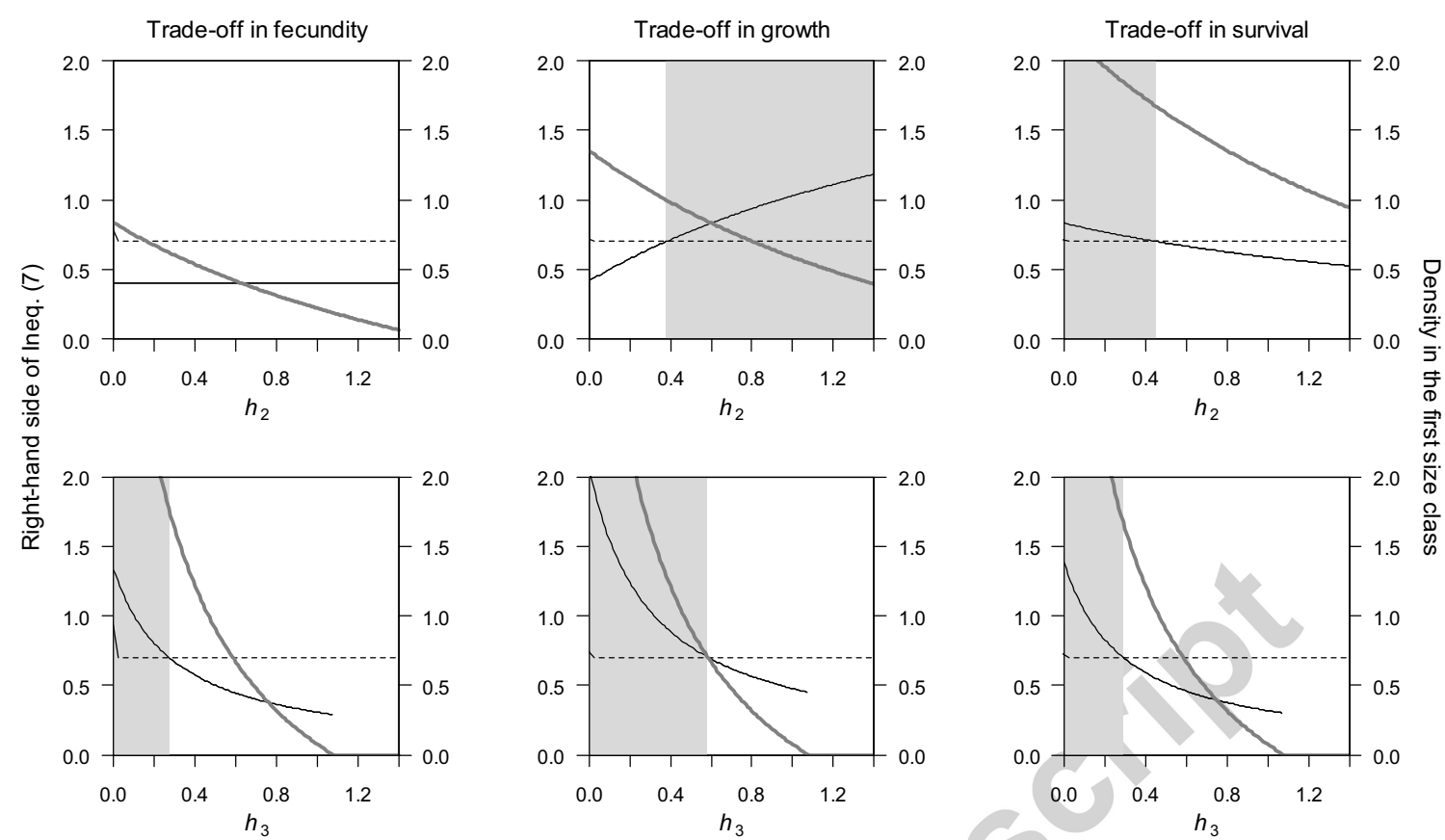

Figure 3. Numerical illustration showing that all predicted outcomes of size-selective harvesting (increasing $h_{2}$ or $h_{3}$ ) are possible. Figure elements are as in Fig. 2. For a trade-off between early maturation and fecundity rate, harvesting the second size class does not affect maturation in either the second or the third size class (top left panel). For a trade-off between early maturation and growth rate, harvesting the second size class promotes late maturation

712 (top center panel). Finally, for a trade-off between early maturation and mortality rate, har713 vesting promotes early maturation (top right panel). Harvesting the third size class always 714 promotes early maturation (bottom panels). Parameter values are provided in Table $\mathrm{C} 1$ of Ap715 pendix C. 

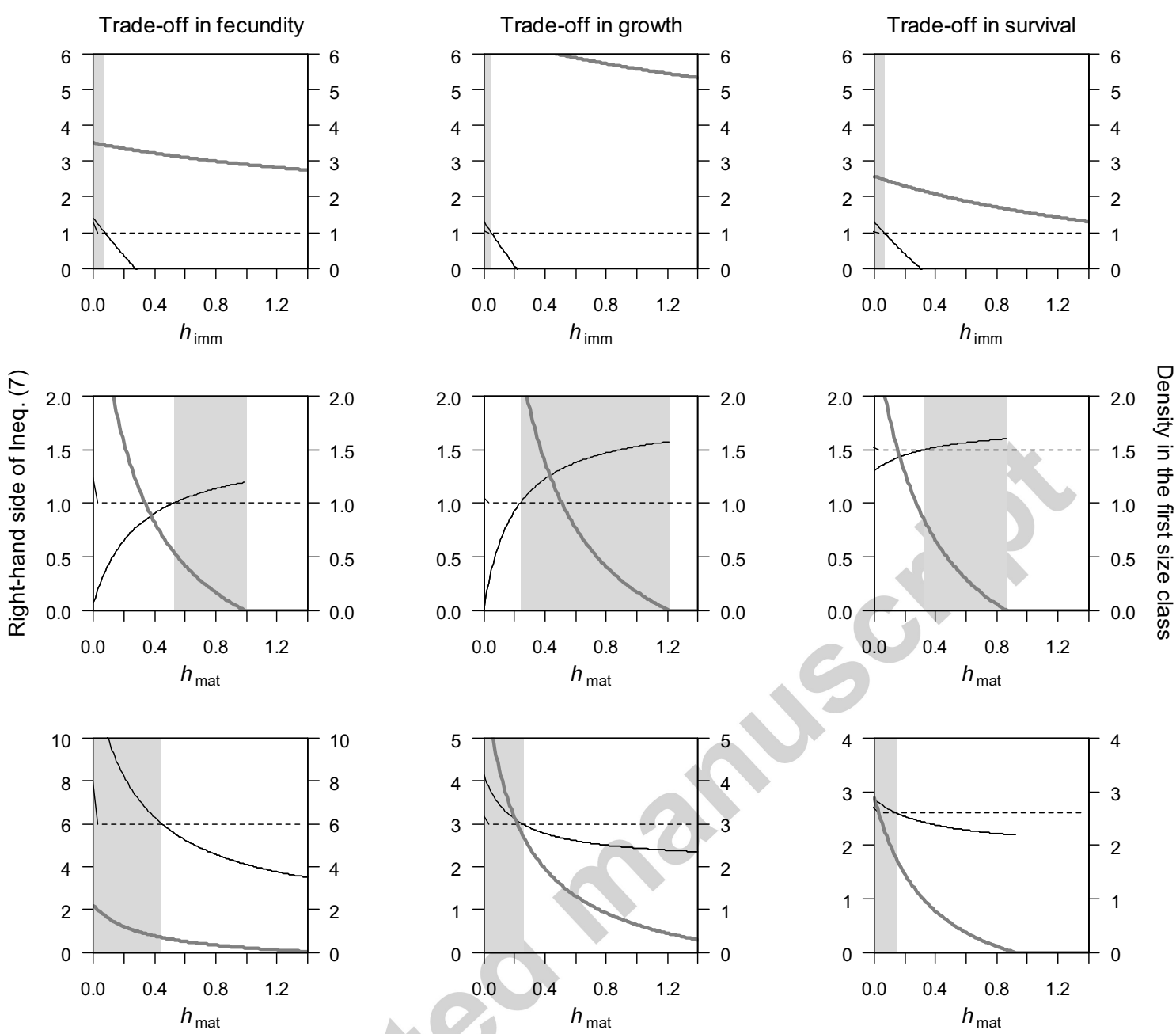

717 Figure 4. Numerical illustration showing that all analytically predicted outcomes of stageselective harvesting (increasing $h_{\mathrm{imm}}$ or $h_{\mathrm{mat}}$ ) are possible. Figure elements are as in Fig. 2. Harvesting immature individuals always promotes early maturation (top panels). For a tradeoff between early maturation and fecundity rate, harvesting mature individuals promotes late maturation when the reduction $f_{3}-\widetilde{f}_{3}$ in fecundity rate is small (middle left panel), and early maturation when $f_{3}-\widetilde{f}_{3}$ is large (bottom left panel). For a trade-off between early maturation and growth rate, harvesting mature individuals always promotes late maturation if the natural mortality in the third size class is larger than the natural mortality in the second size class (not shown). Otherwise, for all three life-history tradeoffs, harvesting mature individuals promotes late maturation when the costs of early maturation are low (middle panels) and early maturation when the costs of early maturation are high (lower panels). Parameter values are provided in Table $\mathrm{C} 1$ of Appendix C. 
730 Table 1. Overview of model variables, parameters, and derived quantities.

\begin{tabular}{|c|c|}
\hline \multirow[t]{2}{*}{ Notation } & Description \\
\hline & Variables \\
\hline$N_{1}$ & Density of individuals in size class 1 \\
\hline$N_{i}$ & Density of late-maturing individuals in size classes $i=2,3$ \\
\hline \multirow[t]{2}{*}{$\tilde{N}_{i}$} & Density of early-maturing individuals in size classes $i=2,3$ \\
\hline & Parameters \\
\hline$\gamma$ & Probability of early maturation \\
\hline$\tilde{f}_{2}$ & Fecundity rate of early-maturing individuals in size class 2 \\
\hline$f_{3}$ & Fecundity rate of late-maturing individuals in size class 3 \\
\hline$\tilde{f}_{3}$ & Fecundity rate of early-maturing individuals in size class 3 \\
\hline$m_{2}$ & Natural mortality rate of late-maturing individuals in size class 2 \\
\hline$\tilde{m}_{2}$ & Natural mortality rate of early-maturing individuals in size class 2 \\
\hline$m_{3}$ & Natural mortality rate of individuals in size class 3 \\
\hline$h_{i}$ & Harvest mortality rate of late-maturing individuals in size classes $i=2,3$ \\
\hline$\tilde{h}_{2}$ & Harvest mortality rate of early-maturing individuals in size class 2 \\
\hline$h_{\text {imm }}$ & Harvest mortality rate of immature individuals \\
\hline$h_{\text {mat }}$ & Harvest mortality rate of mature individuals \\
\hline$r_{1}$ & Growth rate of individuals from size class 1 to size class 2 \\
\hline$r_{2}$ & Growth rate of late-maturing individuals from size class 2 to size class 3 \\
\hline$\tilde{r}_{2}$ & Growth rate of early-maturing individuals from size class 2 to size class 3 \\
\hline & Derived quantities \\
\hline$F_{2}$ & Average fecundity rate of individuals in size class 2 \\
\hline$F_{3}$ & Average fecundity rate of individuals in size class 3 \\
\hline$T_{2}$ & Average time spent by individuals in size class 2 \\
\hline$T_{3}$ & Average time spent by individuals in size class 3 \\
\hline$P_{2}$ & Survival probability from entering size class 1 until entering size class 2 \\
\hline$P_{3}$ & $\begin{array}{l}\text { Survival probability of late-maturing individuals from entering size class } 2 \text { until } \\
\text { entering size class } 3\end{array}$ \\
\hline$\tilde{P}_{3}$ & $\begin{array}{l}\text { Survival probability of early-maturing individuals from entering size class } 2 \text { until } \\
\text { entering size class } 3\end{array}$ \\
\hline
\end{tabular}


$\mathrm{D}_{2} \quad$ Average duration of stay of late-maturing individuals entering size class 2

$\tilde{D}_{2} \quad$ Average duration of stay of early-maturing individuals entering size class 2

$D_{3} \quad$ Average duration of stay of individuals entering size class 3

$f_{2}^{*} \quad$ Threshold for $f_{2}$ above which selection favors early maturation

731 Table 2. Qualitative effects of early maturation on the fecundity and average time spent in the 732 second and third size classes, for the three different life-history trade-offs.

Trade-off of early maturation with

Effect on size class 2 Effect on size class 3

Fecundity

$F_{2} \uparrow$

$F_{3} \downarrow$

Growth

$F_{2} \uparrow T_{2} \uparrow$

$T_{3} \downarrow$

Survival

$$
F_{2} \uparrow T_{2} \downarrow
$$

$T_{3} \downarrow$

Table 3. Evolutionary effects of increased harvest mortality rate. $\downarrow$ indicates that harvesting promotes early maturation, 0 indicates no effect, and $\uparrow$ indicates that late maturation is promoted. $\downarrow / \uparrow$ indicates that harvesting promotes early maturation when the costs of early maturation are low, while late maturation is promoted when the costs of early maturation are high.

Harvesting of

Size class 1

Size class 2

Size class 3

Immature individuals

Mature individuals

\section{Fecundity}

0

0
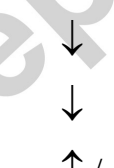

Trade-off of early maturation with

Growth Survival

0

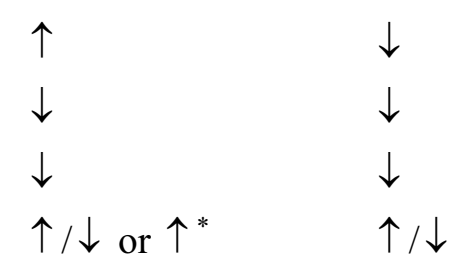

${ }^{*}$ When natural mortality in size class 2 exceeds that in size class 3 , harvesting of mature individuals promotes late maturation independent of the growth costs of early maturation. 
Table C1. Parameter values for Figs. 2-4. Values that change within figures are shown in italics. The left edges of all panels correspond to an unexploited situation: accordingly, harvest rates that are not varied in the panels are set to zero. Notice, however, that the results remain invariant if part of the natural mortality is redistributed to constant harvesting mortality.

\begin{tabular}{|c|c|c|c|c|c|c|c|c|c|}
\hline & Param & & & & & & & & \\
\hline Panel & $m_{1}$ & $m_{2}$ & $\tilde{m}_{2}$ & $m_{3}$ & $r_{2}$ & $\tilde{r}_{2}$ & $\tilde{f}_{2}$ & $f_{3}$ & $\tilde{f}_{3}$ \\
\hline Figure 2 & & & & & & & & & \\
\hline Top left & 0.8 & 0.31 & 0.40 & 1.20 & 1.50 & 1.30 & 0.54 & 2.1 & 1.80 \\
\hline Top centre & 0.8 & 0.31 & 0.40 & 1.20 & 1.35 & 1.15 & 0.54 & 2.1 & 1.80 \\
\hline Top right & 0.8 & 0.30 & 0.40 & 1.20 & 0.80 & 0.67 & 0.54 & 2.1 & 1.80 \\
\hline Bottom left & 0.8 & 0.26 & 0.40 & 1.20 & 1.45 & 1.40 & 0.54 & 2.1 & 1.80 \\
\hline Bottom centre & 0.8 & 0.25 & 0.40 & 1.20 & 1.52 & 1.47 & 0.54 & 2.1 & 1.80 \\
\hline Bottom right & 0.8 & 0.75 & 0.90 & 1.20 & 1.90 & 1.80 & 0.54 & 2.1 & 1.80 \\
\hline Figure 3 & & & & & & & & & \\
\hline Top left & 0.8 & 0.4 & 0.70 & 1.00 & 1.00 & 1.00 & 0.70 & 2.00 & 1.80 \\
\hline Top centre & 0.8 & 0.4 & 0.70 & 0.80 & 1.00 & 1.00 & 0.70 & 2.00 & 1.80 \\
\hline Top right & 0.8 & 0.4 & 0.70 & 0.60 & 1.00 & 1.00 & 0.70 & 2.00 & 1.80 \\
\hline Bottom left & 0.8 & 0.9 & 1.20 & 0.30 & 1.00 & 1.00 & 0.70 & 2.00 & 1.80 \\
\hline Bottom centre & 0.8 & 0.9 & 1.20 & 0.30 & 1.00 & 1.00 & 0.70 & 2.00 & 1.80 \\
\hline Bottom right & 0.8 & 0.9 & 1.20 & 0.30 & 1.00 & 1.00 & 0.70 & 2.00 & 1.80 \\
\hline Figure 4 & & & & & & & & & \\
\hline Top left & 1.3 & 0.60 & 0.60 & 0.60 & 2.00 & 2.00 & 1.00 & 2.20 & 2.00 \\
\hline Top centre & 1.3 & 0.40 & 0.40 & 0.20 & 2.60 & 1.70 & 1.00 & 2.20 & 2.20 \\
\hline Top right & 1.3 & 0.30 & 0.60 & 0.20 & 2.00 & 2.00 & 1.00 & 2.00 & 2.00 \\
\hline Middle left & 1.3 & 0.60 & 0.60 & 0.30 & 2.00 & 2.00 & 1.00 & 2.20 & 2.00 \\
\hline Middle centre & 1.3 & 0.40 & 0.40 & 0.20 & 2.00 & 1.99 & 1.00 & 2.20 & 2.20 \\
\hline Middle right & 1.3 & 0.30 & 0.60 & 0.40 & 2.00 & 2.00 & 1.50 & 2.00 & 2.00 \\
\hline Bottom left & 1.3 & 0.60 & 0.60 & 0.30 & 2.00 & 2.00 & 6.00 & 2.00 & 0.10 \\
\hline Bottom centre & 1.3 & 0.40 & 0.40 & 0.20 & 8.00 & 0.10 & 3.00 & 2.20 & 2.20 \\
\hline Bottom right & 1.3 & 0.10 & 0.70 & 0.40 & 2.00 & 2.00 & 2.60 & 2.00 & 2.00 \\
\hline
\end{tabular}

